\title{
Pre-Emptive Intravenous Diclofenac Sodium for Laparoscopic Tubal Ligation
}

\author{
Dr. Sona Dave Md. Dnb ${ }^{1}$,Dr. Minal Harde Md, Dnb ${ }^{2}$, \\ Dr. Suruchi Sathe. $\mathrm{Md}^{3}$.Dr. Pinakin Gujjar Da, $\mathrm{Md}^{4}$ \\ ${ }^{I}$ Professor * Department Of Anaesthesiology \\ ${ }^{2}$ Associate Professor Department Of Anaesthesiology \\ ${ }^{3}$ Third Year Resident Department Of Anaesthesiology \\ ${ }^{4}$ Professor And Head Department Of Anaesthesiology \\ Topiwala National Medical College \& B.Y L. Nair Ch. Hospital, Mumbai Central, Mumbai
}

\begin{abstract}
Background and Aim: Laparoscopic sterilization is commonly performed procedure and optimum pain relief is necessary for early ambulation and discharge. We aimed to compare the analgesic efficacy of pre-emptive intravenous (IV) diclofenac sodium with intraoperative diclofenac sodium in patients undergoing laparoscopic tubal ligation, to evaluate the requirement of additional analgesics in the postoperative period and to study the time required for ambulation.

Methodology: It was a prospective Randomized Controlled, Double Blinded study done in 60 ASAI and II female patients undergoing laparoscopic tubal ligation under general anaesthesia. These patients were randomly divided in two groups of 30 each. Group A received pre-emptive IV diclofenac sodium (75mg) and group B received intraoperative IV diclofenac sodium (75mg).

Results: There was a significant decrease in postoperative pain in the group who received pre-emptive diclofenac sodium as compared to the group which received intraoperative diclofenac sodium. The statistically significant decrease in both the pain scores was persistent till 24 hours postoperatively. The group receiving pre-emptive diclofenac sodium showed significant reduction in the requirement of rescue analgesic as compared to the other group. Also the ambulation time was significantly less in pre-emptive group. Conclusion we conclude that pre-emptive IV diclofenac sodium was a better analgesic, associated with less postoperative pain, minimal requirement of rescue analgesics with early ambulation and hence shorter recovery time as compared to intraoperative diclofenac sodium in cases of laparoscopic tubal ligation.
\end{abstract}

Keywords: Laparoscopic Tubal Ligation, Pre-Emptive Analgesia, Diclofenac Sodium

\section{Introduction}

Laparoscopic sterilization is one of the commonly performed laparoscopic procedure in gynaecological and obstetric practice. It has many advantages over open procedures, most important being early recovery. ${ }^{1}$ ${ }^{2}$ Howeverinadequate pain control and nausea, vomiting in the early postoperative period may deter early ambulation and discharge from the hospital. ${ }^{2,3}$ Pain after laparoscopic tubal ligation is multifactorial but mainly due to tubal manipulation and ligation leading to increased release of prostaglandins. This pain istherefore amenable to prostaglandin synthetase inhibitors such asnonsteroidal anti-inflammatory drugs (NSAIDs).Diclofenac sodium is most commonly used NSAID which specifically inhibits prostaglandin release. ${ }^{4}$ Generally NSAIDs are given towards the end of procedure with the intention of providing postoperative analgesia. Pre-emptive analgesia is a treatment modality that is initiated before the surgical stimulus in order to reduce nociceptive sensitization. ${ }^{5,6}$ Hencepreoperative IV diclofenac sodium can be hypothesized as a part of multimodal analgesic regimen that would result in decreased opioid consumption and improved analgesia after laparoscopic tubal ligation. ${ }^{5-8}$ Therefore we aimed to compare the analgesic efficacy of preoperative IV diclofenac sodium with intraoperative diclofenac sodium in patients undergoing laparoscopic tubal ligation.Additional parameters like requirement of rescue analgesics in the postoperative period and time required for ambulation were assessed and compared in both the groups.

\section{Methodology}

It was a prospective Randomized Controlled, Double Blinded study, conducted after approval from institutional ethics committee and valid, written, informed consent from patients. Study was carried out in the Obstetrics and Gynaecology operation theatre and general wards of a tertiary care teaching public hospital over a period of 1 year from January 2012 to January 2013. Sixty femalepatients undergoing laparoscopic tubal ligation,American Society of Anesthesiologists(ASA) Grade I, II and weighting 40-60 kgswere included in the study. We excluded patients with known drug allergies, renal impairment, cardiac diseasesand bleeding disorders. 
We studied 60 patients, with 30 in each group A and B. Randomization was done using computergenerated random numbers. Blinding was done by using pre-filled $20 \mathrm{cc}$ syringes with one containing IVdiclofenac sodium $3 \mathrm{ml}$ diluted to $20 \mathrm{ml}$ and the other one containing $20 \mathrm{ml}$ normal saline, which were labelled as "DRUG$\mathrm{X}$ and $\mathrm{Y}$ ". The third party anaesthesiologists not participating in the study was only aware of the contents in $\mathrm{X}$ and $Y$. The observer or patients were not aware of the drug contents in the syringes. The patients were explained about the Visual Analogue Score (VAS) and Categorical Pain Scoring system(CPS). After detailed history and clinical examination and investigations, written informed valid consent was confirmed. IV line was secured with 20 gauge cannula. After computerised randomisation patients received either drug X orY, 2 hours prior to surgery over 5 minutes. Standard balanced anaesthesia technique was then used in both the groups after instituting standard monitoring, preoxygenation and premedication (IV glycopyrrolate $0.004 \mathrm{mg} \mathrm{kg}^{-1}$, ranitidine $1 \mathrm{mg} \mathrm{kg}^{-1}$ and midazolam $0.03 \mathrm{mg} / \mathrm{kg}$ ).

Induction in all patients was done with IV fentanyl 2 microgm $\mathrm{kg}^{-1}$, thiopentonesodium $\left(5-7 \mathrm{mg} \mathrm{kg}^{-1}\right)$ and vecuronium $0.1 \mathrm{mg} \mathrm{kg}^{-1}$. Endotracheal intubation using a direct laryngoscope was performed when adequate relaxation was obtained with appropriate sized endotracheal tube.Maintenance of anaesthesia was done with $\mathrm{O} 2$ + air (50:50) + sevoflurane. Carbon dioxide was used for insufflation and Silicon Band method was used for laparoscopic tubal ligation.

Intraoperatively after tubal ligation but before reversal of anaesthesia patients were again administered study drug over 5 minutes, patients who received drug $\mathrm{X}$ preoperatively now were given drug $\mathrm{Y}$ and vice versa. The drug was administered by a person who was unaware of its contents. At the end of the surgery anaesthesia was reversed using glycopyrolate $(0.008 \mathrm{mg} / \mathrm{kg})$ and neostigmine $(0.05 \mathrm{mg} / \mathrm{kg})$ and patients were extubated.

After extubationpatients were shifted to the post operative recovery room. The presence and severity of pain was assessed systematically by an investigator who was unaware of group allocation. The patients were assessedfor pain at 15, 30, 45 minute, 1, 2, 4, 6, 12,18 and 24 hour after the surgery before discharge. All patients were asked to give scores for their pain at rest and on movement (knee flexion). Pain severity was measured using both VAS $(10 \mathrm{~cm}$ unmarked line in which $0 \mathrm{~cm}=$ no pain and $10 \mathrm{~cm}=$ worst pain imaginable $)$ and CPS (none $=0$; mild $=1$; moderate $=2$; severe $=3$ ). Rescue analgesics - paracetamol $(15 \mathrm{mg} / \mathrm{kg}$ ) was given when VAS was more than 4 . If there was still pain after 30 minutes, inj tramadol $2 \mathrm{mg} / \mathrm{kg}$ was offered as the second rescue analgesic. Time to achieve ambulation (deep breathing, movements from side to side, sitting, leg movement, standing with support and walking with assistance) was noted. The study ended 24 hours after which the patients were discharged. Group A received IV diclofenac sodium (75mg) (drug X) 2 hoursprior to surgery and $20 \mathrm{cc}$ normal saline $(\mathrm{Y})$ intraoperatively while Group B received $20 \mathrm{cc}$ normal saline (Y) prior to surgery and IV diclofenac sodium (75mg) (X) intraoperatively.

\section{Statistical Analysis}

Quantitative data is expressed as Mean, Std Dev, Median and IQR, comparison between study groups is done with the help of Unpaired T test or Mann-Whitney test as per results of Normality test. Qualitative data represented in the form of frequency and percentage andassociation among study group is assessed with the help of Chi-Square test. The number 30 per group was selected on the presumption that most variables will have normal distribution at a sample size of 30. This is based on the central limit theorem.P value was taken as significant when $<0.05$ and $95 \%$ Confidence Interval of that fraction. Data analysis was done with the help of SPSS Software version 15, Statistica 7 and Sigmaplot Version 11.

\section{Results}

Both the groups were comparable with respect to demographic parameters, weight,height,ASA status, etc. No statistically significant difference $(p>0.05)$ was found in both the groups with respect to above factors. The mean VAS pain score in group A and group B at different time interval is depicted in Table 1 and Figure 1 which clearly showsstatistically significant difference ( $\mathrm{P}$ value $<0.001$ ) among both the groups with group A showing significantly better pain relief than group B. The mean CPS pain score in group A and group B at different time interval is mentioned in Table 2 and Figure 2 which evidently shows statistically significant difference ( $\mathrm{P}$ value $<0.001$ ) among both the groups with group A showing significantly better pain relief than group B.

The mean time of receiving first rescue analgesia ( paracetamol) in group A and group B was $133.33+/-31.0$ and 82.0+/-20.58(minutes) respectively (table3, figure 3A). This difference between two groups was statistically significant ( $\mathrm{P}$ value $<0.001$ ). In group $\mathrm{A}$, six out of 30 patients $(20 \%)$ in addition, required tramadol as a second rescue analgesic while 24 out of 30 patients $(80 \%)$ in group B required tramadol as second rescue analgesic. The association was statistically significant ( $\mathrm{p}$ value $<0.001$ )(Table 4 , figure 4 ). The mean ambulation time (hrs) in group A and group B was $4.80+/-0.85$ and $9.40+/-2.16$ respectively (table 3 , figure $3 \mathrm{~B}$ ). The difference in the two groups was statistically significant $(\mathrm{P}$ value $<0.001$ ). 


\section{Discussion}

Pain after laparoscopy is multifactorial resulting from a combination of inflammation, ischemia and tissue trauma at surgical site.In addition, during laparoscopic tubal manipulation or ligation there is release of prostaglandins which may increase the frequency of transmission of nociceptive impulses and cause intense pain. ${ }^{4,9}$ Multimodal analgesic regimens involving opioid analgesics and NSAIDs are mainstay for management of pain associated with out- patient laparoscopic surgeries. ${ }^{5,8}$ Analgesics used for postoperative pain relief should be devoid of troublesome side effects which may delay discharge. Opioids when used for postoperative pain relief are notorious for causing respiratory depression, nausea and vomiting ,deterring discharge. ${ }^{5}$

Pre-emptive analgesia is defined as an intervention given before incision or surgery. It is initiated before the surgical stimulus in order to reduce nociceptive sensitization. Owing to this 'protective' effectof preemptive analgesiaon the nociceptive system, it has the potential to be more effective than a similar analgesic treatment initiated after tissue injury caused by surgery. ${ }^{6,7}$

Several methods of pain relief have been studied in literature. As per available literature most efficacious method for pre-emptive pain control was with epidural analgesia, followed by NSAIDs and local anaesthetic wound infiltration but pre-emptive systemic NMDA antagonists and opioids were not found to be as efficacious. ${ }^{6,7}$ Intravenous NSAIDs are used preemptively in various surgeries as well asintraoperatively, to prevent pain in the early postoperative period. ${ }^{2}$

Diclofenac sodium is an analgesic, antipyretic, anti-inflammatory drug which specifically inhibits prostaglandins. ${ }^{5}$ Prostaglandins act as messenger molecules in the process of inflammation. Most NSAIDs are nonselective inhibitors of cyclooxygenaseenzyme(COX), reversibly inhibiting both the COX-1 and COX-2 isoenzymes. This COX catalyzes the formation of thromboxane andprostaglandinsfrom arachidonic acid...

The current study is a randomised controlled double blinded prospective study in which sixty women undergoing laparoscopic tubal ligation were randomized for pre-emptive IV diclofenac sodium $75 \mathrm{mg}(n=30)$ (group A) versus intraoperative IV diclofenac sodium $75 \mathrm{mg}(n=30)$ (group B). Both the groups were comparable demographically with respect to age, weight and height (table1, figure1). The surgical procedure performed and the average surgical time in both the groups was comparable.

The mean VAS pain score in pre emptive group was significantly lower than intraoperative diclofenacgroup at different time interval (Table 1 and Figure 1). Thus group A showing significantly better pain relief than group B.

The mean CPS pain score in group A and group B at different time interval is mentioned in Table 2 and Figure 2 which shows statistically significant difference among both the groups with group A showing significantly better pain relief than group B.

This is consistent with the findings of Brodie BL et al who suggested that prostaglandins mediate, and when prostaglandin synthetase inhibitor is given as a premedication, it may lessen postoperative pain in patients undergoingFalope ring sterilization. ${ }^{9}$ Similar study conducted by A Mehta et al.showed that preoperative administration of diclofenac $75 \mathrm{mg}$ prior to laparoscopic tubal ligation, resulted in additional analgesic benefits compared with a similar dose given postoperatively but however efficacy of a perioperative analgesic regimen is more important than the preoperative timing of an analgesic intervention alone. ${ }^{2}$ Similar findings were mentioned in other studies also..$^{9-12}$

The mean time for requirement of rescue analgesia was significantly longer in preemptivediclofenac group (table3, figure 3A). IV paracetamol (dose $15 \mathrm{mg} / \mathrm{kg}$ ) was the first rescue analgesic offered andInj tramadol $(2 \mathrm{mg} / \mathrm{kg})$ was given as a second rescue analgesic. Both the groups were offered injparacetamol . However in group B the mean time interval after surgery for requirement of paracetamol was much earlier. Six out of 30 patients (20\%) in group A required tramadol as a second rescue analgesic whereas 24 out of 30 patients $(80 \%)$ in group B required tramadol as a rescue analgesic. The association was statistically significant. Thus the requirement of rescue analgesics was significantly less in group A as compared to group B.It is consistent with the findings of Comfort VK, et al which mentioned that naproxen decreased the postoperative tubal ligation pain resulting in fewer postoperative analgesic requirements, less time to street fitness and no increase in analgesic side-effects. ${ }^{13}$ Gillberg and collegues also stated that diclofenac sodium $50 \mathrm{mg}$ given per rectally 1 hour before the procedure showed significant decrease in both pain intensity and requirement of additional analgesic postoperatively. ${ }^{14}$

The mean ambulation time (hrs) in preemptive group was significantly earlier compared to the intraoperative group. (table3, figure 3B) thus achieving the target of earlier discharge.

Wilmore D W et al stated that bed rest is not recommended as it results in increases muscle loss and weakness, impairs pulmonary function, and predisposes to venous stasis and thromboembolism. ${ }^{3,15}$ All efforts should be made to enforce postoperative movement, which is possible with adequate pain relief. Pre emptive analgesia with diclofenac in our study helps us to achieve this with adequate pain relief. 
As minimally invasive operations are becoming the standard of care, introduction of techniques that reduce the perioperative stress response and optimise pain control will ensure better functional recovery and early discharge and thus reducing the hospital cost and overall burden on the society. ${ }^{10}$

Preventive analgesia is the new term coined for pre - emptive analgesia where pain management strategies are employed before the sensitization with the intention of reducing side effects and facilitating quick recovery and discharge. Itincludes analgesic regimen in the perioperative period given to prevent sensitization induced by pain. ${ }^{6}$ Bilateral rectus sheath block, local anaesthetic infiltration directly to the fallopian tube or into the mesosalpinx have been used with moderate success. ${ }^{14-20}$

However most of them rely on surgical linfiltration methods. Laparoscopic tubal ligations have been performed as a day care surgery with rapid turnovers in a busy gynaecological set up where quick in and out is the norm and requirement. Nevertheless giving intravenous drugs is rapid and under the purview of the anaesthesiologist.Diclofenac is a cost effective and potentpreemptive analgesic which can be a simple method for relief of pain inlaparoscopic tubal ligation.

We conclude Pre-emptive use of NSAID likediclofenac sodium is simple, cost and time effective good option for pain relief, early ambulation and discharge with minimal side effects for laparoscopic tubal ligation procedure.

Authors Contribution:

\begin{tabular}{|l|l|c|c|c|c|c|}
\hline No. & Authors & study design & $\begin{array}{l}\text { conduct of the } \\
\text { study }\end{array}$ & data collection & data analysis & manuscript preparation \\
\hline 1 & $\begin{array}{l}\text { Dr. Sona } \\
\text { Dave }\end{array}$ & yes & yes & yes & yes & yes \\
\hline 2 & $\begin{array}{l}\text { Dr Minal } \\
\text { Harde }\end{array}$ & yes & yes & yes & yes & yes \\
\hline 3 & $\begin{array}{l}\text { Dr. Suruchee } \\
\text { Sathe }\end{array}$ & yes & yes & yes & yes & yes \\
\hline 4 & $\begin{array}{l}\text { Dr. Pinakin } \\
\text { Gujjar }\end{array}$ & yes & No & No & yes & yes \\
\hline
\end{tabular}

\section{References}

[1]. Mahadevappa K, Prasanna N, Channabasappa RA. Trends of Various Techniques of Tubectomy: A Five Year Study in a Tertiary Institute J Clin Diagn Res. 2016;10(1):QC04-7.

[2]. A Mehta, R Bakshi, S Bhasin. Efficacy of Diclofenac Sodium for Post Op Pain Relief in Patients undergoing Laparoscopic Sterilization. The Internet Journal of anesthesiology. 2007 (16); 1.

[3]. Wilmore DW, Kehlet H. Management of patients in fast track surgery.BMJ. 2001:24; 322(7284): 473-6.

[4]. Alexander JI. Pain after laparoscopy. Br. J. Anaesth. 1997;79:369-78.

[5]. Smith HS. Perioperative Intravenous Acetaminophen and NSAIDs Pain Medicine 2011; 12: 961-981.

[6]. Vadivelu N, Mitra S, Schermer E, Kodumudi V, Kaye AD, UrmanRD. Preventive analgesia for postoperative pain control: a broader concept Local Reg Anesth. 2014; 7: 17-22.

[7]. Mishra AK, Afzal M, Mookerjee SS, Bandopadhay KH, Paul A. Pre-emptive analgesia: Recent trends and evidences. Indian J Pain. 2013;27:114-20.

[8]. Kehlet H. Multimodal approach to control postoperative pathophysiology and rehabilitation. Br J Anaesth. 1997;78:606-617.

[9]. Brodie BL, Casper RF. Prostaglandins mediate postoperative pain in Falope ring sterilization. American Journal of Obstetricsand Gynecology1985; 151: 175-177.

[10]. A Corner, R Lightfoot, D James. Ambulatory Surgery, Jan 2006(12); 3;139-42.

[11]. Huang KC, Wolfe WM, Tsueda K, Simpson PM, Caissie KF. Effects of meclofenamate and acetaminophen on abdominal pain following tubal occlusion.American Journal of Obstetrics and Gynecology1986; 155: 624-29.

[12]. Edwards ND, Barclay K, Catling SJ, Martin DG, Morgan RH. Day case laparoscopy: a survey of postoperative pain and an assessment of the value of diclofenac. Anaesthesia 1991; 46: 1077-1080.

[13]. Comfort VK, Code WE, Rooney ME, Yip RW. Naproxen premedication reduces postoperative tubal ligation pain. Canadian Journal of Anaesthesia 1992; 39: 349-352.

[14]. Gillberg LE, Harsten AS, Stahl LB. Preoperative diclofenac sodium reduces postlaparoscopy pain. Canadian Journal of Anaesthesia 1993; 40: 406-8

[15]. Hovorka J, Kallela H, Kortilla K. Effect of intravenous diclofenac on pain and recovery profile after day-case laparoscopy. European Journal of Anaesthesiology 1993; 10: 105-108.

[16]. Buggy DJ, Wall C, Carton EG. Preoperative or postoperative diclofenac for laparoscopic tubal ligation.British Journal ofAnaesthesia 1994; 73: 767-770.

[17]. Cade L, Kakulas P. Ketorolac or pethidine for analgesia after elective laparoscopic sterilization. Anaesthesia and IntensiveCare 1995; 23: 158-161.

[18]. Narchi P, Benhamou D, Aubrun F, Labaille T, Fernandez H. Analgesia using mesosalpinx infiltration combined with intraperitoneallidocaine for Yoon ring laparoscopy. Anesthesiology1992; 77: A17.

[19]. Smith BE, MacPherson GH, de Jonge M, Griffiths JM. Rectus sheath and mesosalpinx block for laparoscopic sterilization. Anaesthesia. 1991; 46: 875-877.

[20]. Power I, Barratt S. Analgesic agents for the postoperative period. Nonopioids.SurgClin North Am. 1999;79:275-97.

[21]. Edwards ND, Barclay K, Catling SJ, Martin DG, Morgan RH. Day case laparoscopy: a survey of postoperative pain and an assessment of the value of diclofenac. Anaesthesia 1991; 46: 1077-1080.

[22]. Comfort VK, Code WE, Rooney ME, Yip RW. Naproxen premedication reduces postoperative tubal ligation pain. Canadian Journal of Anaesthesia 1992; 39: 349-352. 
[23]. Gillberg LE, Harsten AS, Stahl LB. Preoperative diclofenac sodium reduces postlaparoscopy pain. Canadian Journal ofAnaesthesia 1993; 40: 406-8.

[24]. Hovorka J, Kallela H, Kortilla K. Effect of intravenous diclofenac on pain and recovery profile after day-case laparoscopy. European Journal of Anaesthesiology 1993; 10: 105-108.

[25]. Buggy DJ, Wall C, Carton EG. Preoperative or postoperative diclofenac for laparoscopic tubal ligation.British Journal ofAnaesthesia 1994; 73: 767-770.

[26]. Cade L, Kakulas P. Ketorolac or pethidine for analgesia after elective laparoscopic sterilization. Anaesthesia and IntensiveCare 1995; 23: 158-161.

[27]. Narchi P, Benhamou D, Aubrun F, Labaille T, Fernandez H. Analgesia using mesosalpinx infiltration combined with intraperitoneallidocaine for Yoon ring laparoscopy. Anesthesiology1992; 77: A17.

[28]. Smith BE, MacPherson GH, de Jonge M, Griffiths JM. Rectus sheath and mesosalpinx block for laparoscopic sterilization. Anaesthesia.1991; 46: 875-877.

[29]. Power I, Barratt S. Analgesic agents for the postoperative period. Nonopioids.SurgClin North Am. 1999;79:275-97.
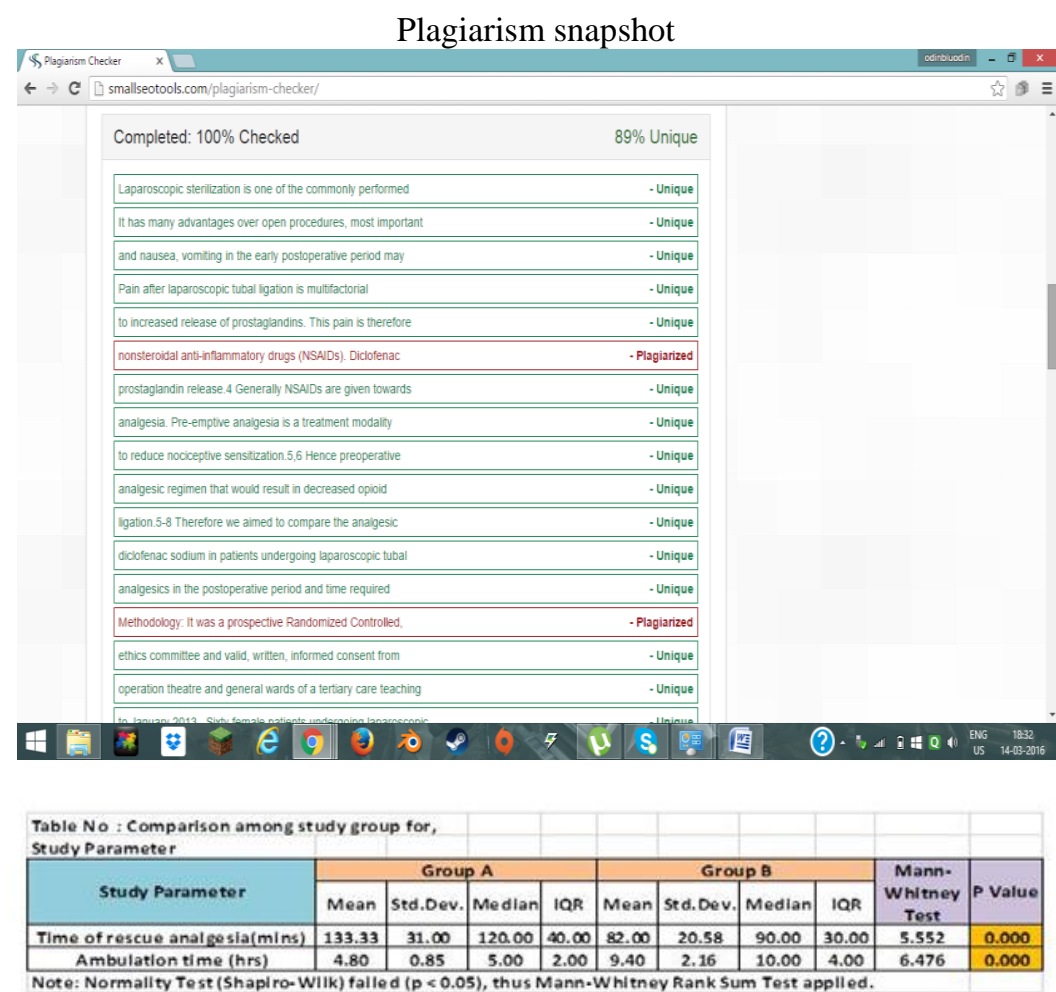

\section{Table No : Comparison among study group for,}

CPS

\begin{tabular}{|c|c|c|c|c|c|c|c|c|c|c|}
\hline \multirow[b]{2}{*}{ CPS } & \multicolumn{4}{|c|}{ Group A } & \multicolumn{4}{|c|}{ Group B } & \multirow{2}{*}{$\begin{array}{c}\text { Mann- } \\
\text { Whitney } \\
\text { Test } \\
\end{array}$} & \multirow{2}{*}{$P$ Value } \\
\hline & Mean & Std.Dev & Median & IQR & Mean & Std.Dev & Median & IQR & & \\
\hline 15 mins & 0.37 & 0.49 & 0.00 & 1.00 & 1.13 & 0.51 & 1.00 & 0.00 & 4.79 & 0.000 \\
\hline 30 mins & 0.43 & 0.50 & 0.00 & 1.00 & 1.17 & 0.53 & 1.00 & 0.25 & 4.51 & 0.000 \\
\hline $45 \mathrm{mins}$ & 1.23 & 0.50 & 1.00 & 1.00 & 1.77 & 0.68 & 2.00 & 1.00 & 3.10 & 0.002 \\
\hline $1 \mathrm{hr}$ & 1.23 & 0.50 & 1.00 & 1.00 & 1.73 & 0.64 & 2.00 & 1.00 & 3.05 & 0.002 \\
\hline $2 \mathrm{hrs}$ & 1.27 & 0.58 & 1.00 & 1.00 & 1.67 & 0.66 & 2.00 & 1.00 & 2.20 & 0.028 \\
\hline 4 hrs & 1.20 & 0.55 & 1.00 & 1.00 & 1.63 & 0.67 & 2.00 & 1.00 & 2.45 & 0.014 \\
\hline 6 hrs & 1.30 & 0.60 & 1.00 & 1.00 & 1.73 & 0.69 & 2.00 & 1.00 & 2.49 & 0.013 \\
\hline $12 \mathrm{hrs}$ & 1.23 & 0.50 & 1.00 & 1.00 & 1.63 & 0.67 & 2.00 & 1.00 & 2.55 & 0.011 \\
\hline $18 \mathrm{hrs}$ & 1.30 & 0.53 & 1.00 & 1.00 & 1.63 & 0.61 & 2.00 & 1.00 & 2.26 & 0.024 \\
\hline $24 \mathrm{hrs}$ & 1.13 & 0.51 & 1.00 & 0.00 & 1.47 & 0.68 & 1.00 & 1.00 & 2.02 & 0.044 \\
\hline
\end{tabular}

Note: Normality Test (Shapiro-Wilk) failed ( $p<0.05$ ), thus Mann-Whitney Rank Sum Test applied. 
Table No : Comparison among study group for,

VAS

\begin{tabular}{|c|c|c|c|c|c|c|c|c|c|c|}
\hline \multirow{2}{*}{ VAS } & \multicolumn{4}{|c|}{ Group A } & \multicolumn{4}{|c|}{ Group B } & \multirow{2}{*}{$\begin{array}{c}\text { Mann- } \\
\text { Whitney } \\
\text { Test }\end{array}$} & \multirow[b]{2}{*}{ P Value } \\
\hline & Mean & Std.Dev. & Median & IQR & Mean & Std.Dev. & Median & IQR & & \\
\hline 15 mins & 0.30 & 0.47 & 0.00 & 1.00 & 1.17 & 0.38 & 1.00 & 0.00 & \begin{tabular}{|r|}
4.990 \\
\end{tabular} & 0.000 \\
\hline 30 mins & 0.40 & 0.50 & 0.00 & 1.00 & 1.33 & 0.48 & 1.00 & 1.00 & 4.879 & 0.000 \\
\hline 45 mins & 0.73 & 0.52 & 1.00 & 1.00 & 1.60 & 0.50 & 2.00 & 1.00 & 4.568 & 0.000 \\
\hline $1 \mathrm{hr}$ & 1.27 & 0.52 & 1.00 & 1.00 & 2.47 & 0.51 & 2.00 & 1.00 & 5.589 & 0.000 \\
\hline 2 hrs & 2.20 & 0.55 & 2.00 & 1.00 & 3.33 & 0.71 & 3.00 & 1.00 & 4.879 & 0.000 \\
\hline $4 \mathrm{hrs}$ & 3.10 & 0.66 & 3.00 & 1.00 & 4.83 & 1.34 & 4.50 & 2.00 & 4.842 & 0.000 \\
\hline $6 \mathrm{hrs}$ & 3.37 & 0.56 & 3.00 & 1.00 & 4.87 & 1.01 & 5.00 & 1.00 & 5.411 & 0.000 \\
\hline $12 \mathrm{hrs}$ & 3.37 & 0.49 & 3.00 & 1.00 & 4.77 & 1.01 & 5.00 & 1.00 & 5.152 & 0.000 \\
\hline 18 hrs & 2.80 & 0.48 & 3.00 & 0.00 & 4.00 & 0.59 & 4.00 & 0.00 & 5.618 & 0.000 \\
\hline 24 hrs & 2.43 & 0.50 & 2.00 & 1.00 & 3.33 & 0.61 & 3.00 & 1.00 & 4.480 & 0.000 \\
\hline
\end{tabular}

Note: Normality Test (Shapiro-Wilk) failed ( $<<0.05$ ), thus Mann-Whitney Rank Sum Test applied.
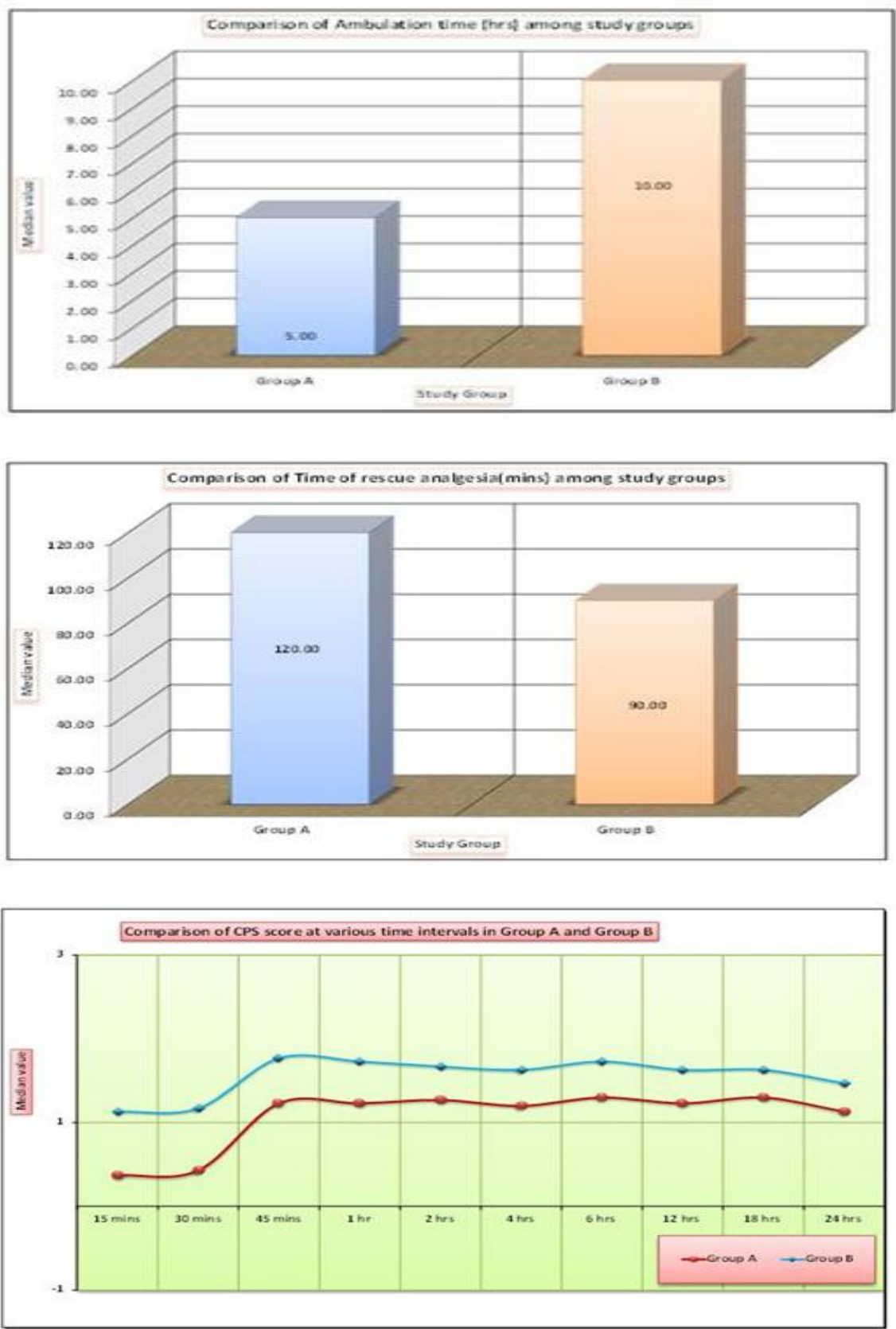


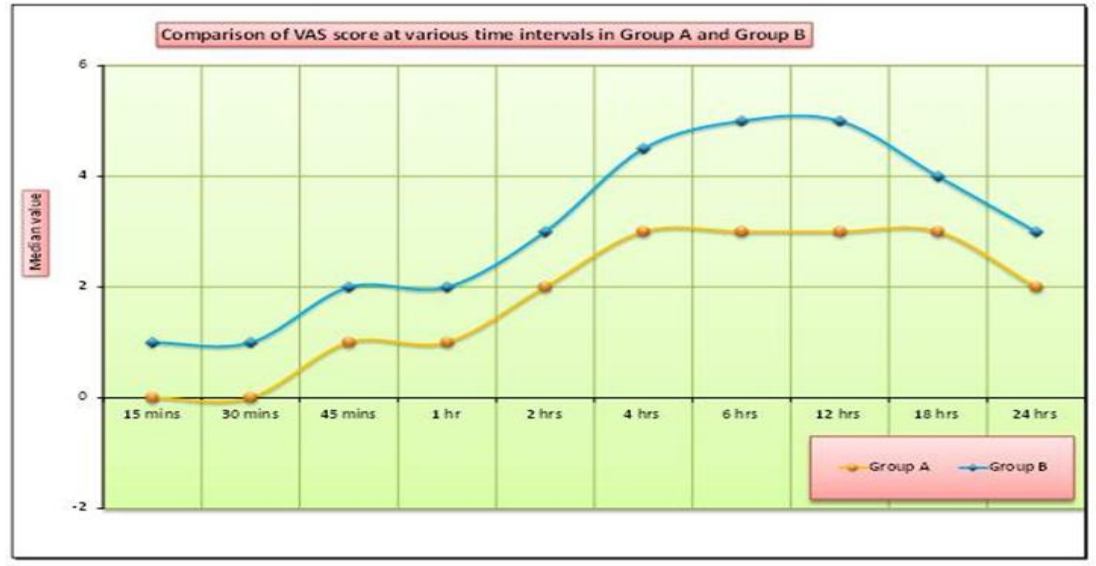

St Group * Requirement of tramadol(Yes/No) Crosstabulation

\begin{tabular}{|c|c|c|c|c|}
\hline \multirow{2}{*}{ StGroup } & & \multicolumn{2}{|c|}{ Requirement of tramadol(Yes/No) } & \multirow{2}{*}{ Total } \\
\hline & & 1) Yes & 2) No & \\
\hline \multirow[t]{2}{*}{ 1)Group $A$} & Count & 6 & 24 & 30 \\
\hline & Percent & $20.00 \%$ & $80.00 \%$ & $100.00 \%$ \\
\hline \multirow[t]{2}{*}{ 2)Group B } & Count & 24 & 6 & 30 \\
\hline & Percent & $80.00 \%$ & $20.00 \%$ & $100.00 \%$ \\
\hline \multirow[t]{2}{*}{ Total } & Count & 30 & 30 & 60 \\
\hline & Percent & $50.00 \%$ & $50.00 \%$ & $100.00 \%$ \\
\hline
\end{tabular}

\begin{tabular}{|c|c|c|c|c|}
\hline Chi-Square Tests & Value & df & P Value & Association is \\
\hline Pearson Chi-Square & 21.6 & 1 & $3.36 \mathrm{E}-06$ & Significant \\
\hline Fisher's Exact Test & & & $6.319 \mathrm{E}-06$ & Significant \\
\hline
\end{tabular}

$<0.001$ 